\title{
Dedication to Professor Malcolm R. Clarke (1930-2013)
}

\author{
Erica A. G. Vidal • Mike Vecchione • \\ Sigurd von Boletzky
}

(C) Springer Science+Business Media Dordrecht 2014

We dedicate this special issue of cephalopods papers to the memory of Professor Malcolm R. Clarke. Malcolm had both the vision and initiative to become the "founding father" of the Cephalopod International Advisory Council (CIAC), and had a fundamental role in uniting the cephalopod research community throughout the 30 years since CIAC was founded. $\mathrm{He}$ was an inspiring mentor and colleague, and an enthusiastic and charismatic person. His outstanding and unique contributions truly made a difference in cephalopod research and will long be remembered. This special issue contains a selected assortment of papers from the CIAC 2012 Symposium held in Florianópolis, Brazil, from 29th October to 2nd November. We believe Malcolm would have read this issue with pleasure.

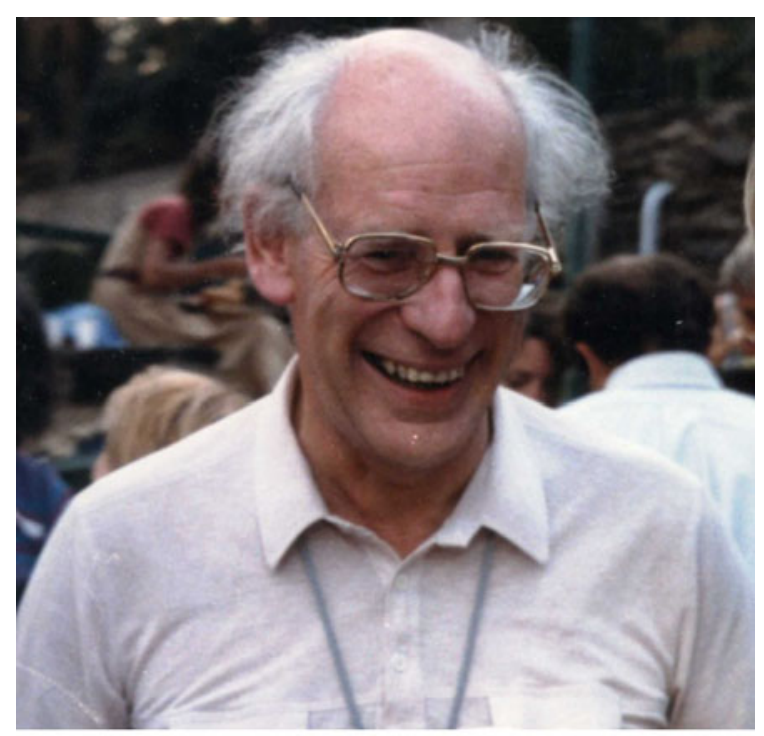

Malcolm R. Clarke (1930-2013)

Guest editors: Erica A. G. Vidal, Mike Vecchione \& Sigurd von Boletzky / Cephalopod Life History, Ecology and Evolution

E. A. G. Vidal $(\bowtie)$

Center for Marine Studies, University of Parana,

Pontal do Paraná, PR, Brazil

e-mail: erica.vidal@ufpr.br

M. Vecchione

NMFS National Systematics Laboratory, National

Museum of Natural History, Smithsonian Institution,

Washington, DC, USA

S. von Boletzky

CNRS, Laboratoire Arago, Banyuls-sur-Mer, France 